\title{
Effectiveness of Anti-Smoking Advertising: The Roles of Message and Media
}

\author{
Yong Hoe Hong ${ }^{1}$, Chin Hooi Soh ${ }^{1}$, Nasreen Khan ${ }^{1}$, Muhammad Madi Bin Abdullah ${ }^{1} \&$ Boon Heng Teh ${ }^{1}$ \\ ${ }^{1}$ Faculty of Management, Multimedia University, 63100, Cyberjaya, Malaysia \\ Correspondence: Yong Hoe Hong, Faculty of Management, Multimedia University, 63100, Cyberjaya, Malaysia. \\ E-mail: yhhong@mmu.edu.my
}

Received: June 5, 2013

doi:10.5539/ijbm.v8n19p55

\author{
Accepted: July 9, 2013 \\ Online Published: September 18, 2013 \\ URL: http://dx.doi.org/10.5539/ijbm.v8n19p55
}

\begin{abstract}
In the last few years, Malaysia government has put in a lot of efforts in order to reduce the number of smokers especially youths in Malaysia. Unfortunately, the numbers of smokers are still increasing according to Global Adult Survey Tobacco (2012). This survey was carried out to evaluate the effectiveness of anti-smoking advertising message and media in Malaysia. A questionnaire was used as a research instrument in this survey. The findings showed that the respondents are "neutral" on the anti-smoking advertising messages except for the fear message. One-way ANOVA and independent samples t-test were used to test the hypotheses. The result from independent samples t-test shows there is a real difference between gender and effectiveness of the anti smoking message. However, the result from one-way ANOVA shows there is no difference between ethnic groups and effectiveness of the anti - smoking message. Besides, the findings also showed that the Internet was the most effective medium to promote anti-smoking advertisements. In future, the comprehensive evaluation of anti-smoking advertising effectiveness in terms of copy, layouts and appeals needs to be studied.
\end{abstract}

Keywords: anti-smoking advertising, message, media, effectiveness

\section{Introduction}

According to Global Adult Tobacco Survey (GATS) (2012), 23.1\% Malaysians aged 15 years above are smokers. The survey also reported that in Malaysia, firstly, adults who noticed anti- cigarette smoking information on the TV or Radio are $87.7 \%$ for smokers and $86.9 \%$ for non-smokers respectively. Secondly, adults who noticed any cigarette advertisement or promotions are $35.7 \%$ for smokers and $29.3 \%$ for non-smokers. Thirdly, adults who believed smoking caused serious illness are $88.1 \%$ of smokers and $93.5 \%$ for non-smokers. Fourthly, adults who believed that smoking should be prohibited indoors or in restaurants are $72.7 \%$ for smokers and $86.7 \%$ for non-smokers. Lastly, adults who believed breathing other people's smoke causes serious illness in non-smokers are $79.8 \%$ for smokers and $87.7 \%$ for non-smokers.

Nearly about 10,000 Malaysians die each year as a result of smoking; World Health Organization (WHO) estimated the tobacco epidemic death toll will be more than 8 million per year globally by 2030 (The Star, 2008). In 2004, Malaysia government launched a "Tak Nak" campaign (an anti-smoking campaign in Malaysia) in order to reduce the number of smokers. Besides, the campaign is also designed to get people to stop smoking and make them aware of the harmful effects of smoking. Unfortunately, based on the GATS survey in 2011, the numbers of smokers in Malaysia are still increasing from year to year. At the same time, more and more youths are becoming smokers and the number of female smokers is also increasing. The government allocated few million for "Tak Nak" anti-smoking campaign, mainly targeting at youths but the result is not encouraging (The Star, 2005). Meanwhile, in the last few years, the "Tak Nak" campaign became less aggressive compared to those years 2004-2008. Besides, a little empirical research has been conducted to measure the effectiveness of "Tak Nak" anti-smoking campaign in Malaysia. This issue has motivated the researchers to embark on this study. Belch \& Belch (2007) and Ferell \& Hartline (2011), the evaluation in term of advertising effectiveness is a major element or task for almost all the marketers. Therefore, it is necessary to measure the effectiveness of "Tak Nak" anti-smoking campaign in order for the government to develop more effective anti-smoking advertisement in future. The aims of this research are: (i) to evaluate the effectiveness of anti-smoking advertising message and media in Malaysia, and (ii) to test the difference between demographic factors and effectiveness of anti-smoking advertising message. 


\section{Literature Review}

Ferell and Hartline (2011), there are few different ways to evaluate advertising namely before, during or after the campaign. Besides, few methods are available to be used to evaluate the effectiveness of advertising such as assessing the effectiveness of advertising message, layouts, copy and media. In this study, the effectiveness of anti-smoking advertising is measured by evaluating the effectiveness of advertising messages and media.

\subsection{Anti-Smoking Advertising Message}

Walsh et al. (2010), in their research found that three different target groups (smokers, non-smokers, and ex-smokers) have a different response towards the advertising messages namely message-involved, message-indifferent and message-distanced. Netemeyer et al. (2005) in their study examined the effects of anti-smoking advertising-based beliefs on adult smokers'. The result showed that for those adult smokers who consider quitting smoking were associated with advertising-based beliefs about smoking addictiveness and the dangers of environmental tobacco smoke. Meyrick (2001), the message of advertising will become more effective if the target audience experiences a feeling of involvement towards the anti-smoking advertisement. Besides, the youths may have an optimistic bias on them. This is because they feel overconfident about themselves and has high self-esteem. Therefore, this will cause the failure of anti-smoking advertising to reach youths due to their optimism bias. A good example of this is that if the youth feels that he or she is healthy enough and does not fear sickness after consuming the cigarettes. So, they will ignore the anti-smoking advertisement. Madden and Dillon (1982) conducted a causal analysis and latent class model on a communication hierarchy of effects model. The study showed that by using the hierarchy of effects model, the advertiser will know which segment is currently effective, whereby creating high awareness for the target audience and for those segments which are not effective. By this the advertiser can attempt to the problem in the future advertising. Mattila (1999) suggested that the advertisement with emotional appeals will generate a high awareness compared to rational. This is mainly due to the advertisement with emotional appeals appearing to strongly influence the attitudes of target audiences.

However, Wolburg (2001) mentioned that the social advertising campaign like anti-smoking is usually not effective. It is because the advertising messages generally encourage consumption rather than discourage consumption behaviors. Besides, Wolburg (2008), the findings mentioned that cessation messages are not offering realistic quit strategies and most of these messages are overly simplistic solutions. As a result, it is a misplaced marketing. Thus, the following hypothesis is suggested:

H1: There is a difference between smokers or non-smokers and effectiveness of anti-smoking advertising message

Wilke et al. (2003), result showed that different ethnic background will perceive the anti-smoking messages differently. Hogg and Garrow (2003) explained that the different gender of audiences may also influence the response towards the advertisement. This is due to male and female audiences perceiving the messages differently. Furthermore, male and female audiences may have different attitudes towards an advertisement. Smith and Stutts (2006) conducted a study to evaluate the influence of individual factors on the effectiveness of message content in anti-smoking advertisement aimed at adolescents. The study showed that both message contents namely health and cosmetics content were influenced by three individual factors which are grade level, gender and ethnicity. Peters et al. (2005) explored the relationship between perceived youth of different race exposure to anti-smoking advertisement. The study found that there is no difference between race and anti-smoking media. In Asia, generally tobacco use differs significant difference the genders (Parkinson, 2009). Thus, the following hypotheses are suggested:

$\mathrm{H} 2$ : There is a difference between genders and effectiveness of anti-smoking advertising message

$\mathrm{H} 3$ : There is a difference between ethnic groups and effectiveness of anti-smoking advertising message

\subsection{Anti-Smoking Advertisement Media}

Media evaluation in term of effectiveness is a key element of marketing communication. An anti-smoking advertising campaign can be considered as effective if it can reduce the number of smokers. Advertising is defined as any paid form of non-personal communication about an organization, product, service or idea through mass media like television, radio, newspapers, magazines, billboard, internet and others (Kotler \& Armstrong, 2012). Belch \& Belch (2007) and Ferell \& Hartline (2011), the evaluation in term of advertising effectiveness is a major element or task for almost all the marketers. The findings of GATS (2012) showed that $87.1 \%$ adults noticed anti-cigarette smoking through broadcasting media such as television and radio. This means that broadcasting media are effective media in providing information to the target audience. 
Metha (2000) mentioned that the target audiences will pay attention if they feel that advertisement is a good way to learn about the product, then they will spend time looking at the advertisement. Pae et al. (2002), in order for advertisement become more effective it also must depend on what products or ideas that are advertised. Pierce et al. (1990), the advertiser needs to select the prime time in order to make the television advertising become more effective. This is mainly due to many target audiences watching the television during this time. Delva et al. (2009) in their study examined the adult awareness of a youth-focused anti-tobacco campaign in Florida US. The findings showed that there is an association between awareness of anti-tobacco campaign theme and intention to quit smoking. Meanwhile, the youth targeted anti-tobacco media campaign is effective in reaching adults who are not smoking. Wakefied et al. (2003) conducted an empirical study on the role of media in influencing trajectories of youth smoking. Besides, this study also emphasized the impact of media messages about smoking to the youths smoking. One of the issues mentioned in this study was that "anti-smoking media messages can also set the agenda for other changes in the community, state or national level. Parkinson et al. (2009) anti-smoking media play a vital role of targeting beliefs about smoking among youth in Malaysia and Thailand. Based on the linear regression result, if the youths are exposed to the anti-smoking media, they are less likely to have a positive belief about not smoking. At the same time, television, radio, posters, billboards and newspapers are effective anti-smoking media in Malaysia because the majority of youths noticed the anti-smoking via these media. On the other hand, Thai youths are usually informed through cinema, the disco and cigarette packs.

However, Weiss et al. (2006), their research found that there are not significant effects through pro-tobacco media exposure such as television, radio, stores and movies and anti-tobacco media exposure. Once the adolescents are exposed to pro-tobacco media, the anti-smoking advertisement is becoming less effective. Wolburg (2001), the public service advertising is usually not successful, due to the media being the wrong platform for promoting anti-consumption message like "don't smoke".

\section{Methodology}

A cross-sectional study was employed in this survey to evaluate the effectiveness of the anti - smoking message in Malaysia. Meyrick (2007) if the target audience for social marketing campaign is younger people; therefore, the research methodology design must be suitable for this group of people.

\subsection{Research Instrument}

The questionnaire in this survey was separated into two sections. For the first section, the questions are regarding the demographic profiles of respondent. In the second section (part A), 5 point response scale ranging from very ineffective (1) to very effective (5) is developed to evaluate the effectiveness of anti-smoking advertising message and for part B, 5 point response scale ranging from strongly disagree (1) to strongly agree (5) is to measure the respondents' perception towards anti-smoking advertising messages and media.

\subsection{Sampling Procedure}

According to GATS (2012) in Malaysia, the oldest smoker's age range 25-44 (55.9\%) followed by 15-24 $(32.50 \%)$. The sample unit in this survey is the undergraduate university students in Malaysia and their age is around 18-25. This sample group was chosen because the main target audiences for an anti - smoking campaign in Malaysia are youths. Besides, these target audiences are easier to quit smoking compared to senior or adult smokers. The sample size of this survey is 150 .

\subsection{Data Collection}

The response rate in this survey was $81.33 \%$. Out of 122 questionnaires collected, only 12 questionnaires were incomplete. As a result, a total of 110 questionnaires is being used in the data analysis.

\section{Results and Discussion}

\subsection{Reliability Test}

The Cronbach's alpha in this survey was 0.90 and quite close to 1.0. This indicated that the internal consistency of reliability in this survey was high (Sekaran, 2000). 


\subsection{Descriptive Analysis}

Table 1. Demographic profiles

\begin{tabular}{ccc}
\hline Variables & Frequency & Percent (\%) \\
\hline Gender & 42 & 38.2 \\
Male & 68 & 61.8 \\
Female & & \\
Age & 19 & 17.3 \\
$18-19$ & 56 & 50.9 \\
$20-21$ & 23 & 20.9 \\
$22-23$ & 12 & 10.9 \\
$24-25$ & & \\
Ethnic & 55 & 50.0 \\
Malay & 34 & 30.9 \\
Chinese & 14 & 12.7 \\
Indian & 7 & 6.4 \\
Others & &
\end{tabular}

Table 1 shows the respondent's profiles in terms of their gender, age, income and ethnic background. The respondents consist of $61.8 \%$ females and 38.2\% males. According to Ministry of Higher Education of Malaysia, the overall intake of local universities in 2011 consists of $35 \%$ male and $65 \%$ female undergraduates (New Straits Times, 2011).Besides, the majority of respondents are age of 20-21 (50.9\%) followed by $22-23$ (20.9\%). The Malay $(50.00 \%)$ was the largest ethnic group in this survey.

Table 2. Number of smokers and non-smokers

\begin{tabular}{rcc}
\hline & Frequency & Percent (\%) \\
\hline Smoker & 9 & 8.2 \\
Non-smoker & 101 & 91.0 \\
\hline
\end{tabular}

Refer to Table 2, majority of the respondents are non-smokers $(91.8 \%)$ and only $8.2 \%$ are smokers. This result can be due to high underreporting among the youth respondents (Parkinson, 2009). The other reason could be the majority of the respondents are aware of the dangers or harm of smoking.

Table 3. Anti-smoking messages

\begin{tabular}{lcc}
\hline & Mean & Standard Deviation \\
\hline Providing useful information & 2.83 & 0.85 \\
Providing educational information & 3.00 & 1.01 \\
Easy to understand & 3.35 & 0.87 \\
Worthwhile to read & 2.92 & 0.97 \\
Fear Message is effective & 2.28 & 0.94 \\
\hline
\end{tabular}

Refer to Table 3, mean for the first four items is close to 3. It showed that that the respondents neither agree nor disagree to pertaining items 1 to 4 . However, the mean for last item is close to 2 . We can conclude that the respondents disagreed that fear message is effective in promoting anti-smoking advertising. The result is consistent with the findings of Malaysia consumer group "fear no longer works when it comes to curbing smoking". This is because the audience becomes immune to this type of message in anti-smoking campaigns (The Star, 2005). Since the fear messages are not effective to promote the anti-smoking advertising, the advertiser can consider using the humor messages. "Humorous advertisements are often the best known and best remembered of all advertising messages". Besides, humorous messages are effective to attract the audience's attention (Belch \& Belch, 2007). 
Table 4. Effectiveness of anti-smoking advertisement media

\begin{tabular}{ccc}
\hline Medium & Mean & Standard Deviation \\
\hline Internet & 3.75 & 0.78 \\
Posters & 3.21 & 0.87 \\
Billboard & 3.11 & 0.90 \\
Television & 3.07 & 0.87 \\
Magazines & 2.97 & 0.92 \\
Radio & 2.84 & 1.00 \\
Newspapers & 2.28 & 0.80 \\
\hline
\end{tabular}

Table 4 shows the most effective medium for anti-smoking was Internet (3.75) followed by poster (3.21). Meanwhile, the least effective medium was newspapers (2.28). This is mainly due to youths being exposed to the anti-smoking advertising via Internet rather than other media. Nowadays, the youths are spending more time on Internet rather than reading newspapers or magazines. This explained why the print media are become less effective in attracting the youth audience's attention. Dahlen et al. (2004) World Wide Web (WWW) advertisements are generally more effective compared to print advertisement. Besides, the popularity of print media will decrease if the Internet penetration into household increases (Belch \& Belch, 2007).

\subsection{Independent Samples T-Test (H1 \& H2)}

Table 5. Smokers/non-smokers and effectiveness of anti-smoking message

\begin{tabular}{cccc}
\hline Smoking & Mean & F-value & Significance \\
\hline Yes (smoker) & 1.89 & 2.60 & 0.03 \\
No (Non-smoker) & 2.68 & & \\
\hline
\end{tabular}

Refer to Table 5, the result showed that the $\mathrm{F}$ value is 2.60 with a significant value of 0.03 . Thus, there is a difference between smokers and non-smokers towards anti-smoking messages. The non-smokers perceived the anti-smoking messages are more effective compared to non-smokers. In order to make the anti-smoking advertising messages become more effective, the advertiser needs to have different copies of messages for smokers and non-smokers.

Table 6. Gender and effectiveness of anti-smoking message

\begin{tabular}{cccc}
\hline Gender & Mean & F-value & Significance \\
\hline Male & 2.19 & 2.047 & 0.001 \\
Female & 2.88 & & \\
\hline
\end{tabular}

Refer to Table 6, the result from independent samples t-test showed that the F value is 2.047 with a significant value of 0.01 . Thus, the hypothesis H1 was significant. That means there is a real difference between male and female towards the effectiveness of anti-smoking messages. Female respondents normally are more willing to spend their time reading the anti-smoking messages compared to male respondents. Moreover, they generally believed these messages are useful or important to them.

4.4 One-Way ANOVA (H3)

Table 7. Ethnic groups and effectiveness of anti-smoking message

\begin{tabular}{cccc}
\hline Ethnic Groups & Mean Square & F-value & Significance \\
\hline Between & 0.375 & 0.355 & 0.785 \\
Within & 1.055 & & \\
\hline
\end{tabular}


Refer to table 7, the result from one-way ANOVA showed that the $\mathrm{F}$ value is 0.355 with a significant value of 0.785. Thus, the hypothesis $\mathrm{H} 3$ was not significant. This indicated that there is no difference between ethnic groups and effectiveness of anti-smoking advertising message.

\section{Managerial Implications}

\subsection{Message}

Martin (2002), to make the advertisement become more effective, the advertisers have to use customer's testimonials or expert comments to attract the target audiences towards advertisements. Priester \& Petty (2003), the spokesperson trustworthiness on the message elaboration will influence the target audience's response towards advertisement. In Malaysia, the advertiser should use spokespersons like "Datuk" Lee Chong Wei (current Badminton world ranking no.1), Nicole David (current Squash world ranking no.1), Pandelela Rinong anak Pamg (first Malaysian female Olympics medal winner in 2012) to attract the youths to the anti-smoking advertisements. Indirectly, these spokespersons are also promoting healthy lifestyle and encouraging the youths to participate in sports activities. In order for fear message to be more effective, it should be credible and perceived to be accepted by the youth audience. The message should also not be threatening. This is mainly because too extreme fear message can cause negative feelings and unwanted defensive behaviors among youth audiences. Besides, the advertisers need to make sure that their anti-smoking messages are attractive and creative enough to attract the youth audiences.

The advertiser should display the anti-smoking messages that are more focused on educating the target audiences instead of just informing them. To increase the awareness of youths towards the anti-smoking advertising messages, the advertiser should provide clear, powerful and concise information. According to Metha (2000), the target audiences who had a positive feeling toward advertising will seemed to recall more compared those who had a negative feeling. As such, the new anti-smoking advertising messages should able to create a positive feeling among the youth audiences. Comparative advertising is advertising that focuses on messages with direct or indirect promotional comparison. The advertiser can use side-by-side comparison between smoking and non-smoking. For smokers, the advertiser can show the negative consequences of smoking. Meanwhile, for non-smokers, the advertiser can show the benefits of non-smoking.

\subsection{Media}

According to the findings, Internet is the most effective medium to promote anti-smoking advertisements. To select the right media is one of the most challenging tasks for the advertiser. Nowadays, the social network is the fastest growing in Malaysia and world. Therefore, the advertiser should use social networks like Facebook, Twitter, and others to promote the anti-smoking advertisements. The religion is very effective in changing people's values, beliefs and attitudes. The holy places like mosque, temple, church and others are good place for outdoor media especially billboard. The advertiser should display the anti-smoking advertisements posters in these areas.

\section{Limitation and Future Research}

This survey only evaluates the effectiveness of anti-smoking message and ignores the impact of advertising copy, layouts, execution techniques and appeal. Besides, this survey is only focused on undergraduate students, and the majority of them are not smokers. In last few years (2009-2012), the anti-smoking advertising campaigns are less aggressive compared to those years in 2004-2008. Respondents need more time to recall the anti-smoking advertising messages. In future, anti-smoking advertising campaign should also evaluate the effectiveness of advertising copy, layouts, execution techniques and appeal. Besides, only the youth smokers should be targeted as respondents. Longitudinal studies should be employed instead of cross-sectional studies because it is better to evaluate the same respondents over a period of time.

\section{Conclusion}

This survey was carried out to evaluate the effectiveness of anti-smoking advertisements campaigns in terms of the roles of message and media in Malaysia. The result postulated that the respondents are "neutral" on the anti-smoking messages except the fear message. Besides, Internet was perceived as the most effective medium in promoting anti-smoking advertisements.

The findings of the study assist the Malaysia government to develop more effective anti-smoking advertisements and messages in future. The Government could take more effective strategies such as to use spokespersons in anti-smoking advertisements, use social network as the main medium to promote the anti-smoking advertisement, and display the anti-smoking messages that are more focused on educating instead of just informing the target audiences. 


\section{References}

Belch, E. G., \& Belch, A. M. (2007). Advertising and promoting: an integrated marketing communications perspective (7th ed.). McGraw-Hill: New York.

Dahlen, M., Murray, M., \& Nordenstam, S. (2004). An empirical study of perceptions of implicit meanings in world wide wide advertisement versus print advertisements. Journal of Marketing Communications, 10(1), 35-47. http://dx.doi.org/10.1080/1352726042000177391

Delva, J., Dietz, A. N., Perron, B., Sanchez, N., \& Wolley, E. M. (2009). Adult awarenwss of a youth focused anti-tobacco campaign: does having children matter? Informa Healthcare, 44, 763-774.

Ferell, C. O., \& Hartline, D. M. (2011). Marketing management strategies (5th ed.). South-Western: Canada.

Global Adult Tobacco Survey. (2012). Fact sheet of Malaysia 2011.

Hogg, K. M., \& Garrow, J. (2003). Gender, identity and the consumption of advertising. Qualitative Market Research: An International Journal, 6(3), 166-174.

Kotler, P., \& Armstrong, G. (2012). Principles of marketing (14th ed.). Pearson: London.

Madden, J. T., \& Dillon, R. W. (1982). Analysis and latent class models: an application to a communication hierarchy of effects model. Journal of Marketing Research, 16, 472-490. http://dx.doi.org/10.2307/3151721

Martin, S. A. B., Bhimy, C. A., \& Agee, T. (2002). Infomercials and advertising effectiveness: an empirical study. Journal of Consumer Marketing, 19(6), 468-480. http://dx.doi.org/10.1108/07363760210444850

Mattila, S. A. (1999). Do emotional appeals work for services? International Journal of Service Industry Management, 10(3), 292-306. http://dx.doi.org/10.1108/09564239910276890

Metha, A. (2000). Advertising attitudes and advertising effectiveness. Journal of Advertising Research.

Meyrick, D. J. (2001). Forget the "blood and gore": an alternative message strategy to help adolescents avoid cigarette smoking. Health Education, 101(3), 99-107. http://dx.doi.org/10.1108/09654280110387862

Meyrick, D. J. (2007). The internet in social marketing research. Journal of Nonprofit and Public Sector Marketing, 17(1/2), 103-120. http://dx.doi.org/10.1300/J054v17n01_05

Netemeyer, G. R., Andrews, C. J., \& Burton, S. (2005). Effects of anti-smoking advertising- based beliefs on adult smokers' consideration of quitting. American Journal of Public Health, 95(6), 1062-1066. http://dx.doi.org/10.2105/AJPH.2004.050195

Pae, H. J., Samiee, S., \& Tai, S. (2002). Global advertising strategy: the role of brand familiarity and execution style. International Marketing Review, 19(2), 176-189. http://dx.doi.org/10.1108/02651330210425024

Parkinson, M. C., Hammond, D., Fong, T. G., \& Borland, R. (2009). Smoking beliefs and behavior among youth in Malaysia and Thailand. American Journal of Health Behavior, 33(4), 366-376. http://dx.doi.org/10.5993/AJHB.33.4.3

Peters, J. R., Kelder, H. S., Prokhorov, A., Amos, C., Yacoubian, S. G., Agurcia, A. C., Murray, N., \& Shegog, R. (2005). The relationship between youth exposure to anti-smoking advertisement: how perceptions differ by race. Journal of Drug Education, 35(1), 47-58. http://dx.doi.org/10.2190/8063-QP4L-T5A5-B207

Pierce, P. T., Macaskill, P., Stat, M., \& Hill, D. (1990). American Journal of Public Health, 80(5), 565-569. http://dx.doi.org/10.2105/AJPH.80.5.565

Priester, R. J., \& Petty, E. R. (2003). The influence of spokesperson trustworthiness on message elaboration, attitude strength, and advertising effectiveness. Journal of Consumer Psychology, 13(4), 408-421. $\mathrm{http}: / / \mathrm{dx}$.doi.org/10.1207/S15327663JCP1304_08

Sekaran, U. (2000). Research methods for business: a skill building approach (3rd ed.). Wiley: New York.

Smith, H. K. \& Stutts, A. M. (2006). The influence of individual factors on the effectiveness of content in anti-smoking advertisements aimed at adolescents. The Journal of Consumer Affairs, 40(12), 261-293. http://dx.doi.org/10.1111/j.1745-6606.2006.00058.x

The Star. (2005). Anti-smoking fear tactics has failed.

The Star. (2005). Government saying "tak nak" to "Tak Nak" campaign.

The Star. (2008). Just stop smoking: strategies to keep you quit smoking successfully. 
The Straits Times. (2011). Female undergrads outnumber males: Malaysia.

Wakefield, M., Flay, B., Nichter, M., \& Giovino, G. (2003). Role of the media in influencing trajectories of youth smoking. Society for the Study of Addiction to Alcohol \& other Drugs, 98(1), 79-103. http://dx.doi.org/10.1046/j.1360-0443.98.s1.6.x

Walsh, G., Hassan, M. L., Shiu, E., Andrews, C. J., \& Hastings, G. (2010). Segmentation in social marketing: insights for the European Union's multi-country, anti-smoking campaign. European Journal of Marketing, 44(7/8), 1140-1164. http://dx.doi.org/10.1108/03090561011047562

Weiss, W. J., Cen, S., Schuster, V. D., Unger, B. J., Johnson, A. C., Maitappa, M., Schreiner, S. W., \& Cruz, B. T. (2006). Nicotine \& Tobacco Research, 8(3), 455-465. http://dx.doi.org/10.1080/14622200600670454

Wilkem, M. K., Turner, L. K., \& Giuliano, A. T. (2003). Smoke screens: cross-cultural effectiveness of anti-smoking messages. North America Journal of Psychology, 5(3), 431-442.

Wolburg, M. J. (2001). Misplaced marketing: why television is the "wrong" environment for public service advertising campaigns. Journal of Consumer Marketing, 18(6), 471-473. http://dx.doi.org/10.1108/EUM0000000006153

Wolburg, M. J. (2008). Smoking cessation: why do smokers fail? Journal of Consumer Marketing, 25(2), $72-73$. http://dx.doi.org/10.1108/07363760810858800

\section{Copyrights}

Copyright for this article is retained by the author(s), with first publication rights granted to the journal.

This is an open-access article distributed under the terms and conditions of the Creative Commons Attribution license (http://creativecommons.org/licenses/by/3.0/). 